\title{
Identification of RNA Binding Partners of CRISPR-Cas Proteins in Prokaryotes Using RIP-Seq
}

\author{
Sahil Sharma and Cynthia M. Sharma
}

\begin{abstract}
CRISPR-Cas systems consist of a complex ribonucleoprotein (RNP) machinery encoded in prokaryotic genomes to confer adaptive immunity against foreign mobile genetic elements. Of these, especially the class 2, Type II CRISPR-Cas9 RNA-guided systems with single protein effector modules have recently received much attention for their application as programmable DNA scissors that can be used for genome editing in eukaryotes. While many studies have concentrated their efforts on improving RNA-mediated DNA targeting with these Type II systems, little is known about the factors that modulate processing or binding of the CRISPR RNA (crRNA) guides and the trans-activating tracrRNA to the nuclease protein Cas9, and whether Cas9 can also potentially interact with other endogenous RNAs encoded within the host genome. Here, we describe RIP-seq as a method to globally identify the direct RNA binding partners of CRISPRCas RNPs using the Cas9 nuclease as an example. RIP-seq combines co-immunoprecipitation (coIP) of an epitope-tagged Cas9 followed by isolation and deep sequencing analysis of its co-purified bound RNAs. This method can not only be used to study interactions of Cas9 with its known interaction partners, crRNAs and tracrRNA in native systems, but also to reveal potential additional RNA substrates of Cas9. For example, in RIP-seq analysis of Cas9 from the foodborne pathogen Campylobacter jejuni (CjeCas9), we recently identified several endogenous RNAs bound to CjeCas9 RNP in a crRNA-dependent manner, leading to the discovery of PAM-independent RNA cleavage activity of CjeCas9 as well as non-canonical crRNAs. RIP-seq can be easily adapted to any other effector RNP of choice from other CRISPR-Cas systems, allowing for the identification of target RNAs. Deciphering novel RNA-protein interactions for CRISPR-Cas proteins within host bacterial genomes will lead to a better understanding of the molecular mechanisms and functions of these systems and enable us to use the in vivo identified interaction rules as design principles for nucleic acid-targeting applications, fitted to each nuclease of interest.
\end{abstract}

Key words CRISPR-Cas, Prokaryotes, Campylobacter jejuni, Cas9, RNA-immunoprecipitation, Next-generation sequencing

1 Introduction

Post-transcriptional regulation represents an important layer of gene expression control in uni- and multicellular organisms. Hereby, RNA molecules (rRNA, mRNA, tRNA, and non-coding 
RNAs) as well as RNA-binding proteins (RBPs) and ribonucleases (RNases) are central players in mediating and regulating gene expression. Most RNA molecules associate with proteins for exerting this control and co-exist as ribonucleoprotein (RNP) complexes. RNP complexes can execute numerous cellular functions including gene regulation, RNA modifications, mRNA translation, and RNA stability control $[1,2]$. Studying these RNPs enables us to understand the role of RBPs and RNases in cellular physiology. Moreover, with the advent of numerous RNA-sequencing (RNAseq) approaches using deep sequencing technologies it has become possible to study and analyze these RNPs on a transcriptome-wide scale in diverse organisms, including bacteria, and dissect their complex biological tasks $[3,4]$.

One diverse and widespread group of RNP complexes used by prokaryotes are the CRISPR-Cas (Clustered Regularly Interspaced Short Palindromic Repeats and CRISPR-associated) systems. These RNA-based prokaryotic immune systems are present in approximately half of bacterial and $85 \%$ archeal genomes, which have evolved over the course of many years to create an immunological memory, guided by the incorporated nucleic acids, forming the basis of an organism's adaptive immunity [5-7]. Such CRISPRCas adaptive immune systems have been extensively studied over the last decade for their role as defense systems in prokaryotes to protect against foreign mobile genetic elements such as phages and plasmids and more recently as tools for enabling precise genome editing in various organisms [8-10]. CRISPR-Cas systems primarily function in the form of active RNPs with Cas nuclease effector complexes, which are guided by CRISPR RNA (crRNA) guides encoded in CRISPR repeat-spacer arrays to target and destroy specific DNA/RNA sequences. CRISPR-Cas systems are divided into two broad classes, with class I systems being composed of multiple Cas proteins, which form the core effector module, whereas class II systems comprise a single, multidomain effector nuclease [11]. Each class of CRISPR-Cas is further divided into three types each, i.e., types I, III, and IV forming class 1 , and types II, V, and VI in class 2. Each type further contains subtypes based on variations either in structure or function of CRISPR-Cas genes. CRISPR-Cas immune systems work by incorporating foreign DNA fragments, known as spacers into the host genome between specific repeat regions in the genome-the CRISPR locus. Once the spacers are acquired into these repeats, they are transcribed and processed into individual crRNAs, which interact with Cas proteins and mediate RNA-guided genome defense [12, 13]. Hereby, the sequence of the crRNAs defines the specificity of the adaptive immune response, both for the host and its progeny. This adaptive immune response can be achieved by targeting either DNA or RNA. While RNA targeting is specific to Type III and VI systems, DNA targeting is mediated by Type I, II, and V systems. Type III 
CRISPR-Cas systems are the only exception that can target invading nucleic acids at the level of both DNA and RNA.

Of the six types of CRISPR-Cas systems, Cas9 nucleases from class 2, Type II are currently the most widely used for RNA-guided genome editing and various technological applications in bacterial and eukaryotic genomes $[8,14,15]$. This system uses a single Cas 9 nuclease for targeting double-stranded DNA, using a crRNA guide and endonuclease activity of Cas9 via its RuvC and $\mathrm{HNH}$ nuclease domains [16, 17]. Type II-A, II-B, and II-C systems differ based on the size of their Cas9 protein and the presence of associated additional cas genes [18]. In addition to crRNA guides, Type II systems also require the presence of a trans-activating crRNA (tracrRNA) [19]. The tracrRNA has base-pairing complementarity to the repeat region of the crRNA guide and mediates processing and maturation of crRNAs via processing by the host factor RNase III. Moreover, tracrRNA is also required for Cas 9 function as the mature tracrRNA-crRNA duplex is bound by Cas9, thereby guiding the Cas9:crRNA:tracrRNA RNP to a protospacer in the target DNA flanked by a protospacer-adjacent motif (PAM) [20]. For the purpose of genome editing, a chimeric RNA formed by the fusion of crRNA and tracrRNA called the single-guide RNA ( $\operatorname{sgRNA}$ ) is used, thus simplifying the system further [16].

Type II systems are widespread in pathogenic and commensal bacteria and there is emerging evidence that they could have additional functions beyond genome defense [21]. These unconventional functions are not restricted to Type II systems alone and involve regulation of bacterial virulence, group behavior dynamics, genome remodeling, DNA repair, antisense RNAs, and selftargeting mechanisms in numerous CRISPR-Cas types [2229]. It is well known that Cas9:crRNA:tracrRNA RNP surveils the cytoplasm and targets DNA from invading genomes, but whether Cas9 has additional RNA partners involved in regulating host gene expression, remains unclear. Recently, the Cas9 homolog in Francisella novicida (FnoCas9) has been identified to target its own DNA with the help of a small CRISPR/Cas associated RNA termed scaRNA, leading to RNA-directed transcriptional repression [30]. Moreover, recent studies also indicate that certain members of the Cas9 family are capable of targeting RNA [14]. For example, using RNA co-immunoprecipitation combined with RNA-sequencing (RIP-seq) of epitope-tagged Cas9 from Campylobacter jejuni (CjeCas9), we recently uncovered that the CjeCas9 nuclease is capable of binding and cleaving endogenous RNAs in vivo, in addition to binding its canonical crRNA:tracrRNA pairs [31]. This crRNA-dependent targeting of endogenous RNAs is PAM-independent. Also, other Type II Cas9 family members from Neisseria meningitidis (NmeCas9) and Staphylococcus aureus (SauCas9) were shown to target single-stranded RNAs independently of a PAM in vitro [32, 33]. Moreover, Cas9 from 
Streptococcus pyogenes (SpyCas9) can target RNA after addition of single-stranded DNA oligonucleotides with a PAM sequence in vitro and has been applied in human cells for RNA tracking and localization by replacing the active enzyme with catalytically dead SpyCas9 in vivo [34, 35]. These studies showed that even within the Type II system, Cas9 homologs from different species can have a variety of molecular activities. Moreover, while a lot of studies have concentrated on RNA-mediated DNA targeting with Type II Cas9 systems and its tremendous technological applications, very little is known about how these systems regulate activity of the RNA-guided effector nucleases and about their potential interactions with other RNAs encoded within the host genomes. With the exception of CjeCas9 and FnoCas9, most studies have described CRISPR-Cas Type II proteins in vitro or expressed exogenously in eukaryotic cells or other bacteria, which while providing valuable insights also limits the mechanistic understanding of these effector molecules in bacteria natively harboring these systems.

Here, we describe the so-called RIP-seq approach to identify the direct RNA substrates of CRISPR-Cas RNPs in prokaryotes (Fig. 1). RIP-seq combines co-immunoprecipitation (coIP) of an epitope-tagged RBP followed by isolation and deep sequencing analysis of its co-purified bound RNAs. Prior to the development of high-throughput sequencing technologies, co-purified transcripts from coIPs of RBPs were typically analyzed with either high-density microarrays or conventional low-throughput $\mathrm{RNo}^{-}$ mics using direct RNA-sequencing or Sanger sequencing to identify, e.g., the targetome of the RNA chaperone Hfq in Escherichia coli, Listeria monocytogenes, and Pseudomonas aeruginosa, respectively [36-38]. The combination of coIP with RNA-seq for RIP-seq analyses of Hfq then allowed for identifying its small RNA (sRNA) and messenger RNA binding partners in Salmonella on a transcriptome-wide scale and with single-nucleotide resolution [39]. RIP-seq has also been successfully adapted and applied to study the regulons of a number of other RNA-binding proteins in bacterial species such as E. coli, C. jejuni, Helicobacter pylori, and N. meningitidis [40-47]. Using a similar coIP approach combined with deep sequencing in organisms harboring Type III CRISPRCas systems identified mature crRNAs bound to the effector proteins, which shed light into the mechanism governing targeting of both host and foreign RNAs in those systems [23, 48].

Based on RIP-seq to examine the direct RNA binding partners of the Cas9 nuclease of the foodborne pathogen C. jejuni, we had identified the abovementioned RNA-targeting activity of CjeCas9 and more recently also discovered non-canonical crRNAs [31, 67]. Hereby, we built on a RIP-seq protocol previously adapted for the use in Epsilonproteobacteria [40-47]. Using a genetically modified strain of C. jejuni expressing a 3xFLAG epitope at the C-terminus of CjeCas9 (CjeCas9-3xFLAG) at the 
Identifying RNA substrates of CjeCas9 by RIP-seq

WT and chromosomally 3xFLAG tagged $C$. jejuni strains

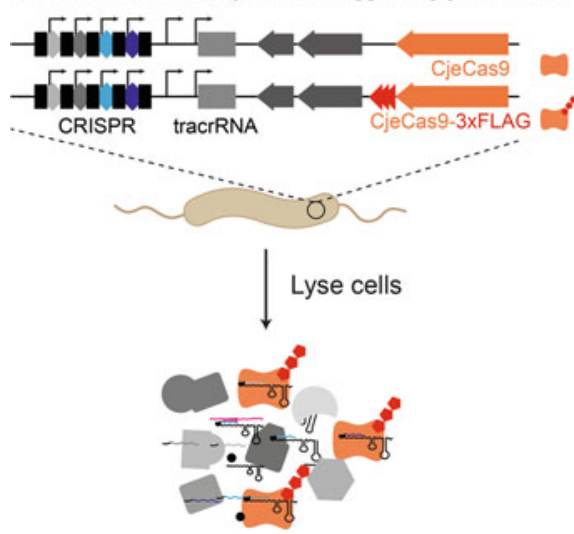

Incubate

FLAGantibody

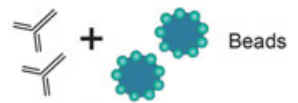

Immunoprecipitate
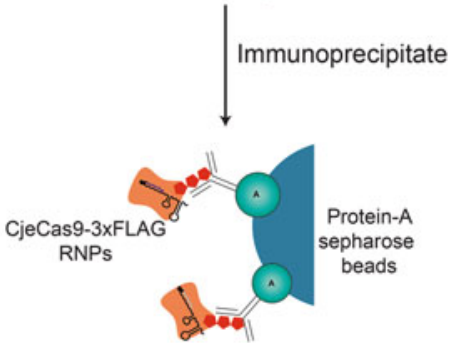

$\downarrow$ Elute

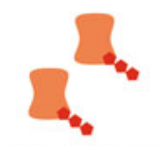

Protein eluate

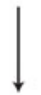

Western blot

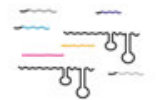

RNA eluate

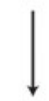

Northern blot/ cDNA library

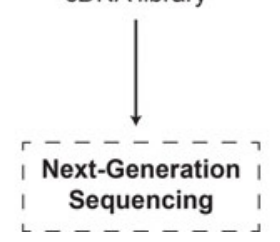

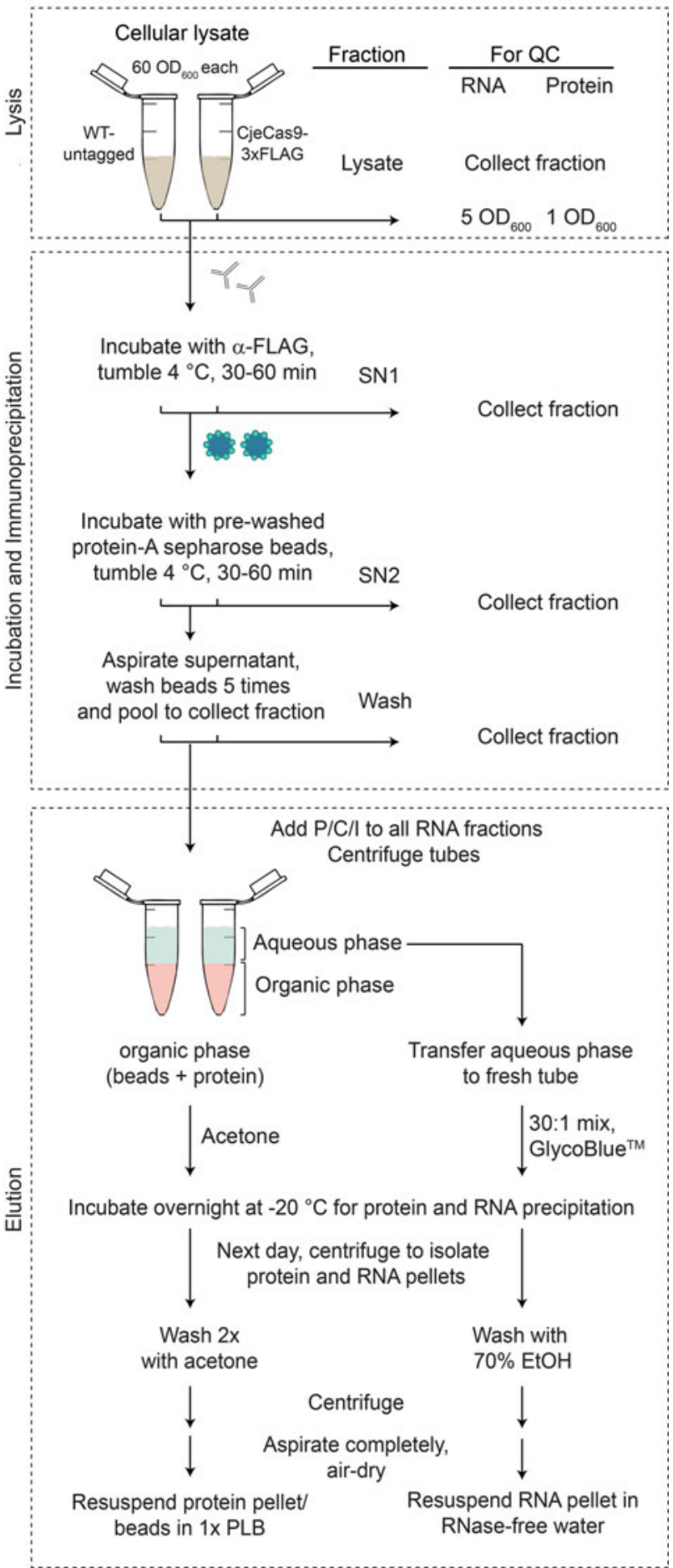

Fig. 1 RIP-seq analysis to identify the direct RNA substrates of Cas9 in $C$. jejuni. (Leff) Schematic representation of co-immunoprecipitation of 3xFLAG-tagged CjeCas9. (Right) Detailed overview of the RIP-seq protocol used to identify CjeCas9-bound RNAs in C. jejuni strain NCTC11168. Bacterial lysates prepared from cell pellets corresponding to a cell number of $600 \mathrm{D}_{600}$ pellets using WT-untagged and CjeCas9-3xFLAG tagged 
native locus and an antibody against the FLAG epitope allowed for immunoprecipitation and isolation of native ribonucleoprotein complexes comprised of CjeCas9-3xFLAG bound crRNA: tracrRNA and other endogenous RNAs. The parallel use of a WT-untagged strain as a negative control allows for discriminating enriched RNAs that are specifically bound to CjeCas9-3xFLAG from RNAs that are nonspecifically bound to the beads or the antibody during the coIP procedure as background noise. The use of an epitope tag allows for immunoprecipitating a protein of interest in the absence of a mono-/polyclonal antibody against the protein itself. Deep sequencing analysis of the transcripts co-purified with CjeCas9-3XFLAG revealed that the majority correspond to tracrRNA and crRNAs, indicating successful pull-down of Cas9-crRNA-tracrRNA complexes. Surprisingly, a fraction of endogenous transcripts, including many mRNAs, were also enriched in the CjeCas9-3xFLAG coIP, and we could demonstrate that CjeCas9 can bind and cleave single-stranded RNAs in a crRNA-dependent manner and that non-canonical crRNA guides can be derived from mRNAs [31, 67]. Similar as for studying RNA binding partners of CjeCas9, RIP-seq can be readily applied to any bacterial species of choice (Gram-positive or Gram-negative), harboring a CRISPR-Cas system and capable of genetic manipulation (chromosomally or via plasmids), for transcriptome-wide identification of RNAs interacting with the CRISPR-Cas protein of interest. A better understanding of the different CRISPR-Cas RNP complexes will facilitate deciphering their underlying molecular principles of function and to use them for further improving the biotechnological application of these systems.

\section{Materials}

\subsection{Bacterial Strains}

For the RIP-seq analysis, C. jejuni NCTC11168 wildtype (WT) as well as a CjeCas9-3xFLAG strain are used. The C. jejuni strain with a 3xFLAG-tagged CjeCas9 at the native locus was constructed using a double-stranded DNA construct and double-crossover homologous recombination, as described previously [31]. Hereby, the cas 9 ( $\mathrm{Cj} 1523 \mathrm{c})$ gene was chromosomally tagged at its

Fig. 1 (continued) bacterial cells grown to exponential phase are used as the starting material for co-immunoprecipitation. This is followed by incubation with an anti-FLAG antibody, protein A-sepharose beads and washing to enrich for CjeCas9-3xFLAG RNPs. CjeCas9-3XFLAG protein and bound RNAs are separated using phenol/chloroform/isoamyl alcohol, precipitated, and eluted into protein and RNA fractions. Lysate, supernatant 1 (SN1), supernatant 2 (SN2), and wash fractions are collected during the course of the experiment along with the final eluate. All samples are used for quality control before proceeding with DNase I digestion and next-generation sequencing of eluted RNAs 


\subsection{Bacterial Culture and Collection}

\subsection{RNA CO- immunoprecipitation}

C-terminus by introducing overlap PCR products containing 500 bp homologous ends encompassing a 3xFLAG sequence (DY KDHDGDYKDHDIDYKDDDDK ) and a kanamycin resistance marker using electroporation into the C. jejuni NCTC11168 WT strain.

1. Müller-Hinton agar plates and Brucella broth (BB), both supplemented with $10 \mu \mathrm{g} / \mathrm{mL}$ vancomycin. The agar was further supplemented with marker-selective antibiotics $(50 \mu \mathrm{g} / \mathrm{mL}$ kanamycin) when required.

2. Resuspension buffer (Buffer A): $20 \mathrm{mM}$ Tris- $\mathrm{HCl}, \mathrm{pH}$ 8.0, $150 \mathrm{mM} \mathrm{KCl}, 1 \mathrm{mM} \mathrm{MgCl} 2$ with $1 \mathrm{mM}$ Dithiothreitol (DTT) (added freshly each time before use).

3. $1 \times$ Protein loading buffer $(1 \times$ PLB $): 62.5 \mathrm{mM}$ Tris $-\mathrm{HCl}$, $\mathrm{pH}$ 6.8, $100 \mathrm{mM}$ DTT, 10\% (v/v) Glycerol, 2\% (w/v) SDS, $0.01 \%(\mathrm{w} / \mathrm{v})$ Bromophenol blue.

1. Buffer A.

2. Lysis buffer (per mL): $967 \mu \mathrm{L}$ Buffer A (without DTT), $1 \mu \mathrm{L}$ $1 \mathrm{mM}$ DTT, $10 \mu \mathrm{L} \quad 0.1 \quad \mathrm{M}$ Phenylmethylsulfonylflouride (PMSF), $2 \mu \mathrm{L}$ Triton X-100, $20 \mu \mathrm{L}$ DNase I, and $10 \mu \mathrm{L}$ Superase-In RNase Inhibitor.

3. $5 \times$ Protein loading buffer.

4. Eppendorf tubes $(2 \mathrm{~mL}$ and $1.5 \mathrm{~mL})$.

5. Fast-prep tubes with lysing Matrix B.

6. FastPrep-24 ${ }^{\mathrm{TM}}$ benchtop Homogenizer (MP Bio).

7. Monoclonal anti-FLAG M2 antibody $(1 \mathrm{mg} / \mathrm{mL})$.

8. Protein A-sepharose beads.

9. GlycoBlue ${ }^{\mathrm{TM}}$.

10. Roti-Aqua-P/C/I (phenol/chloroform/isoamyl alcohol).

11. RNA precipitation mix (30:1): Ethanol:3M NaOAc, $\mathrm{pH} 6.5$.

12. $70 \%$ Ethanol (stored at $-20^{\circ} \mathrm{C}$ ).

13. Acetone (stored at $-20{ }^{\circ} \mathrm{C}$ ).

14. RNase-free water.

1. Antibodies: Monoclonal anti-FLAG antibody (1:1000 \#F1804 Sigma-Aldrich) and anti-GroEL (1:10,000 \#G6532 SigmaAldrich). Horseradish peroxidase-coupled anti-mouse IgG secondary antibody $(1: 10,000)$ and anti-rabbit $\operatorname{IgG}$ secondary antibody $(1: 10,000)$.

2. SDS-Polyacrylamide gels and electrophoresis equipment and buffers for western blots. 
3. Polyacrylamide/Urea gels and electrophoresis equipment and buffers for northern blots.

4. RNA loading buffer II: 95\% Formamide, $18 \mathrm{mM}$ Ethylenediaminetetraacetic acid (EDTA), $0.025 \% \mathrm{w} / \mathrm{v}$ each of SDS, Xylene Cyanol and Bromophenol Blue.

5. DNase I.

6. $10 \times$ DNase I buffer containing $\mathrm{MgCl}_{2}$.

7. Superase-In RNase Inhibitor.

8. Phase-lock tubes.

\section{Methods}

\subsection{Bacterial Culture and Pellet Collection}

1. Inoculate bacterial cultures of C. jejuni NCTC11168 WT control and the corresponding CjeCas9-3xFLAG strain in $100 \mathrm{~mL}(50 \mathrm{~mL} \times 2$ flasks $)$ Brucella broth containing $10 \mathrm{mg} / \mathrm{mL}$ vancomycin to the selected growth phase, e.g., mid-exponential growth $\left(\mathrm{OD}_{600}=0.5-0.6\right)$ at $37{ }^{\circ} \mathrm{C}$ under microaerobic $\left(10 \% \mathrm{CO}_{2}, 5 \% \mathrm{O}_{2}\right)$ conditions as previously described [31] (see Notes 1-4).

2. Harvest cells by centrifugation at $6000 \times g$ at $4{ }^{\circ} \mathrm{C}$ for $15 \mathrm{~min}$ using a refrigerated benchtop centrifuge. Resuspend cell pellets in $1 \mathrm{~mL}$ Buffer A (ice-cold), transfer to $1.5 \mathrm{~mL}$ eppendorf tube, and centrifuge at $11,000 \times \mathfrak{g}, 4{ }^{\circ} \mathrm{C}$ for $3 \mathrm{~min}$ using a refrigerated microcentrifuge. Aspirate the supernatant as cleanly as possible and immediately snap-freeze the pellets in liquid nitrogen. Store the pellets at $-80^{\circ} \mathrm{C}($ see Note 5$)$.

1. Thaw frozen pellets (see Subheading 3.1, step 2) on ice and resuspend in $1 \mathrm{~mL}$ Lysis buffer by gentle pipetting. Transfer the $1 \mathrm{~mL}$ lysate from each sample onto one fast-prep tube for lysis (see Note 6). Place tubes on ice and avoid RNase contamination.

2. Perform lysis with FastPrep- $24^{\mathrm{TM}}$ benchtop homogenizer (MP Bio) at settings of $4 \mathrm{M} / \mathrm{s}, 15 \mathrm{~s}$ and clear the lysate in the fast-prep tube by centrifugation at $15,000 \times \mathfrak{g}, 4^{\circ} \mathrm{C}$ for $10 \mathrm{~min}$ to remove cellular debris generated during mechanical lysis ( see Note 7).

3. Transfer the cleared lysate into a pre-chilled $2 \mathrm{~mL}$ eppendorf tube without disturbing the debris at the bottom and place the tube on ice. Measure the volume of the lysate collected and aliquot volumes equivalent to 1 and $5 \mathrm{OD}_{600}$ for protein and RNA, respectively. As an example, for a lysate volume of approximately $700 \mu \mathrm{L}$ collected from $60 \mathrm{OD}_{600}$ culture, $11.5 \mu \mathrm{L}\left(1 / 60 \mathrm{OD}_{600}\right)$ for protein and $58 \mu \mathrm{L}\left(5 / 60 \mathrm{OD}_{600}\right)$ 
volume for RNA are transferred to chilled $2 \mathrm{~mL}$ eppendorf tubes. For the protein aliquot, add $38.5 \mu \mathrm{L}$ buffer $\mathrm{A}$ and $50 \mu \mathrm{L}$ of $5 \times$ Protein loading buffer to adjust to a final volume of $100 \mu \mathrm{L}$ or $0.01 \mathrm{OD}_{600} / \mu \mathrm{L}$. For the RNA aliquot, adjust the volume to $500 \mu \mathrm{L}$ with Buffer $\mathrm{A}$ and store the tubes on ice (Fig. 1). These aliquots represent the amount of protein and RNA present in the sample after lysis and will be needed for quality control of the immunoprecipitation experiment (see Note 8).

4. Take the remaining lysate and add $35 \mu \mathrm{L}$ anti-FLAG monoclonal antibody per tube. Incubate for $30-60 \mathrm{~min}$ at $4{ }^{\circ} \mathrm{C}$, gently tumbling the tube (Fig. 1). While the antibody is incubated with the lysate, pre-wash $75 \mu \mathrm{L}$ Protein A-Sepharose beads per sample with $500 \mu \mathrm{L}$ of Buffer A by gently inverting tubes and centrifugation at $15,000 \times g$ for $1 \mathrm{~min}$ at $4{ }^{\circ} \mathrm{C}$. Wash at least three times to saturate the beads with Buffer A (see Note 9).

5. After 30-60 min incubation with the anti-FLAG antibody, aliquot volumes equivalent to 1 and $5 \mathrm{OD}_{600}$ for protein and RNA, respectively (see Subheading 3.2, step 3). These aliquots are labeled as supernatant $1(\mathrm{SNl})$ and stored at $-20{ }^{\circ} \mathrm{C}$ for later use (Fig. 1).

6. After aliquoting $\mathrm{SN1}$, transfer the rest of the supernatant to a fresh $2 \mathrm{~mL}$ tube containing $75 \mu \mathrm{L}$ of pre-washed Protein A-sepharose beads per sample and incubate with gentle tumbling for 30-60 min at $4{ }^{\circ} \mathrm{C}$ (Fig. 1) ( see Note 10).

7. After $30-60 \mathrm{~min}$ incubation, centrifuge at $15,000 \times \mathfrak{g}, 4^{\circ} \mathrm{C}$ for 1 min to spin down the beads and transfer the supernatant, now referred to as supernatant 2 (SN2) into fresh $2 \mathrm{~mL}$ tubes, without losing any beads (Fig. 1). From SN2, take an aliquot equivalent to 1 and $5 \mathrm{OD}_{600}$ for protein and RNA quality control, respectively ( see Note 11 ).

8. Wash the $2 \mathrm{~mL}$ eppendorf tube containing the beads with $500 \mu \mathrm{L}$ Buffer A. Mix gently by inverting the tube (3-5 times) and centrifuge at $15,000 \times g, 4{ }^{\circ} \mathrm{C}$ for $1 \mathrm{~min}$. Discard the first wash fraction and repeat this step four times (Fig. 1). Collect fractions after each washing step into one tube (approx. $2 \mathrm{~mL}$ collected from four washes) for aliquoting protein and RNA samples equivalent to 1 and $5 \mathrm{OD}_{600}$, respectively (see Note 12).

9. After the last washing step, add $500 \mu \mathrm{L}$ Buffer A to the $2 \mathrm{~mL}$ eppendorf tube containing the beads. Subsequently, add $500 \mu \mathrm{L}$ phenol/chloroform/isoamyl alcohol (P/C/I) to separate protein and RNA fractions from the beads into aqueous and organic phase (Fig. 1). This tube is labeled as the elution fraction (see Note 13). 
10. Similarly, add $500 \mu \mathrm{L} \mathrm{P} / \mathrm{C} / \mathrm{I}$ to all $2 \mathrm{~mL}$ eppendorf tubes on ice containing RNA aliquots collected during the course of the experiment, i.e., Lysate, SN1, SN2, and Wash aliquots (Fig. 1). The protein fractions collected during the course of the experiment in the $5 \times$ Protein loading buffer can be transferred to $-20{ }^{\circ} \mathrm{C}$ for storage and later use.

11. Shake all tubes containing $\mathrm{P} / \mathrm{C} / \mathrm{I}$ vigorously for $15 \mathrm{~s}$ and incubate for $5 \mathrm{~min}$ at room temperature (Fig. 1).

12. Centrifuge at $15,000 \times \mathfrak{g}, 4^{\circ} \mathrm{C}$ for $30 \mathrm{~min}$.

13. After separation of the aqueous and organic phase, transfer the aqueous phase (on top) from all aliquots into fresh $2 \mathrm{~mL}$ eppendorf tubes containing $1 \mathrm{~mL}$ of 30:1 mix of Ethanol:3 M sodium acetate and $1 \mu \mathrm{L}$ GlycoBlue ${ }^{\mathrm{TM}}$. Store the tubes overnight at $-20{ }^{\circ} \mathrm{C}$ for RNA precipitation (Fig. 1).

14. To the tube containing the Protein A-sepharose beads in organic phase (at bottom), add $1.4 \mathrm{~mL}$ acetone (ice-cold) and incubate overnight at $-20{ }^{\circ} \mathrm{C}$ for protein precipitation.

RNA extraction:

15. On the next day, centrifuge the tubes containing the aqueous phases with $30: 1 \mathrm{mix}$ of Ethanol:3M sodium acetate at $15,000 \times g, 4{ }^{\circ} \mathrm{C}$ for $30 \mathrm{~min}$.

16. Carefully remove supernatant with a pipette without disturbing the pellet and wash once with $500 \mu \mathrm{L}$ of ice-cold $70 \%$ EtOH. Centrifuge at $15,000 \times g, 4{ }^{\circ} \mathrm{C}$ for $10 \mathrm{~min}$. Carefully aspirate $\mathrm{EtOH}$ without touching the pellet (see Note 14).

17. Air-dry the pellets at room temperature in a laminar hood and resuspend them in $30 \mu \mathrm{L}$ RNase-free water. Dissolve the pellet by heating the samples at $65^{\circ} \mathrm{C}$ for $5 \mathrm{~min}$ on a heat block with constant shaking at $800 \mathrm{rpm}$ and then store at $-20^{\circ} \mathrm{C}$ (Fig. 1). Use $5 \mu \mathrm{L}$ for verification of successful coIP via northern blot analysis.

Protein extraction:

18. On the next day, centrifuge the tubes containing the beads and acetone at maximum speed $\sim 21,000 \times g, 4{ }^{\circ} \mathrm{C}$ for $60 \mathrm{~min}$.

19. Carefully remove the supernatant and wash twice with $1 \mathrm{~mL}$ ice-cold acetone at maximum speed at $4{ }^{\circ} \mathrm{C}$ for $30 \mathrm{~min}(\mathrm{see}$ Note 15).

20. Remove supernatant and air-dry the pellets at room temperature. Afterwards, resuspend in $120 \mu \mathrm{L}$ of $1 \times$ Protein loading buffer. Boil the elution samples for $8 \mathrm{~min}$ at $95{ }^{\circ} \mathrm{C}$ on a heat block with constant shaking at $800 \mathrm{rpm}$ and store at $-20{ }^{\circ} \mathrm{C}$ (Fig. 1). 
3.3 Quality Control for Verification of Successful CjeCas9$3 \times F L A G$

Immunoprecipitation

\subsubsection{Western Blot}

\subsubsection{Northern Blot}

\subsection{DNase I Treatment}

Prior to DNase I digestion, cDNA synthesis, and RNA-sequencing, the amount of immunoprecipitated CjeCas9-3xFLAG protein as well as co-purified crRNA and tracrRNA can be visualized by western and northern blot analysis, respectively (Fig. 2). This allows for quality control before proceeding with cDNA library preparation and next-generation sequencing (see Note 16).

1. Boil protein samples stored at $-20{ }^{\circ} \mathrm{C}$ from all collected aliquots at $95{ }^{\circ} \mathrm{C}$ using a heat block with constant shaking at $800 \mathrm{rpm}$ for $5-8 \mathrm{~min}$.

2. $20 \mu \mathrm{L}$ volume each from lysate, SN1, SN2, wash, and eluate fractions (corresponding to $0.2 \mathrm{OD}_{600}$ for $\mathrm{L}, \mathrm{SN} 1, \mathrm{SN} 2, \mathrm{~W}$, and $10 \mathrm{OD}_{600}$ for eluate, i.e., $1 / 6$ of a final of $120 \mu \mathrm{L}$ lysate derived from $60 \mathrm{OD}_{600}$ starting material) is used for western blot analysis after resolving on 10\% SDS-PAGE. The blots are probed using monoclonal anti-FLAG and anti-GroEL antibodies (Fig. 2a). For western blot, a protocol can be found here [49].

1. Transfer $5 \mu \mathrm{L}$ volume of RNA from a total of $30 \mu \mathrm{L}$ collected per fraction into a fresh $1.5 \mathrm{~mL}$ eppendorf tube, i.e., one each for Lysate, SN1, SN2, wash, and eluate.

2. Add $5 \mu \mathrm{L}$ of RNA loading buffer II to all the tubes containing $5 \mu \mathrm{L}$ RNA, for both WT control and CjeCas9-3xFLAG tagged samples.

3. Denature the mix at $95{ }^{\circ} \mathrm{C}$ on a heat block for $2 \mathrm{~min}$ and separate RNA samples by gel electrophoresis using a $6 \%$ PAA/7 M urea gel.

4. Transfer RNA from the PAA gel to a Hybond-XL membrane (GE-Healthcare) by electroblotting. After blotting, cross-link RNA to the membrane using UV irradiation and proceed with northern blotting to detect tracrRNA and crRNA3 in the eluted fractions as described previously (Fig. 2b) [31]. A protocol for northern blotting can be found here $[50,51]$.

Prior to cDNA library preparations and after quality control, the remaining RNA samples must be treated with DNase I to remove any residual genomic DNA.

1. Denature $25 \mu \mathrm{L}$ of the remaining RNA eluate samples at $65^{\circ} \mathrm{C}$ on a heat block for $5 \mathrm{~min}$. Afterwards, transfer the tube to ice for another $5 \mathrm{~min}$.

2. Add $5 \mu \mathrm{L}$ of $10 \times$ DNase I buffer containing $\mathrm{MgCl}_{2}, 0.5 \mu \mathrm{L}$ Superase-In RNase Inhibitor, and $5 \mu \mathrm{L}$ DNase I. Fill the total reaction volume to $50 \mu \mathrm{L}$ by adding $14.5 \mu \mathrm{L}$ of RNase-free water. 
A

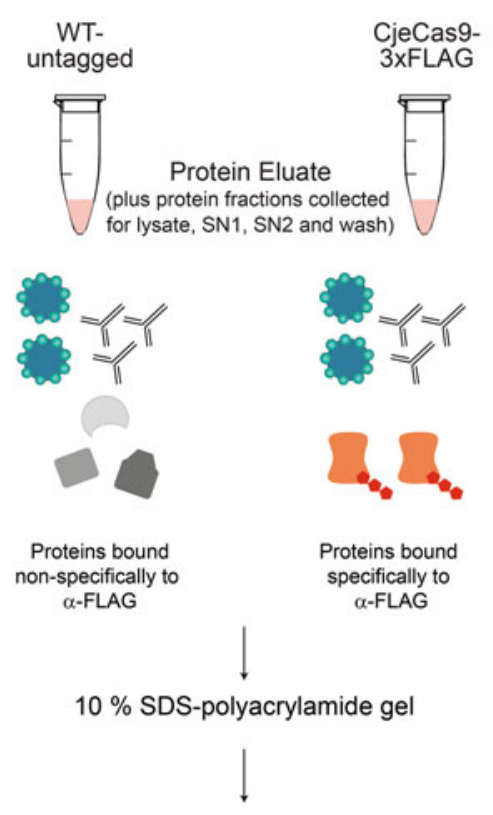

Western Blot

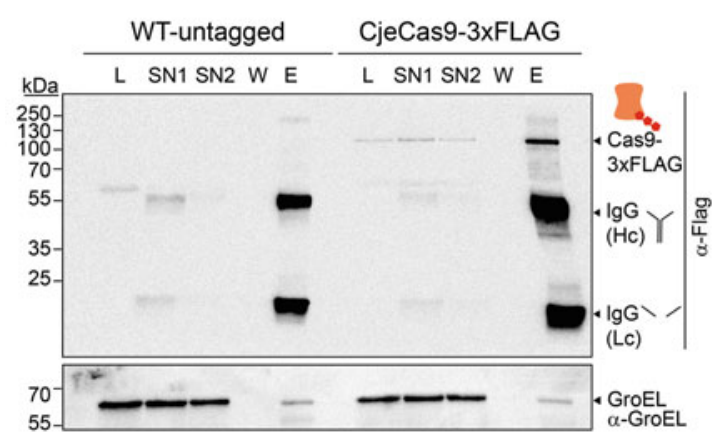

B
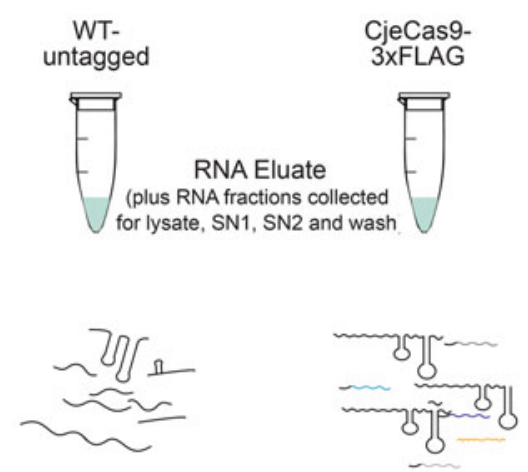

RNAs bound to beads/antibody

RNAs bound to FLAG-tagged CjeCas9 RNPs

$6 \%$ Polyacrylamide/7M Urea gel

Northern Blot

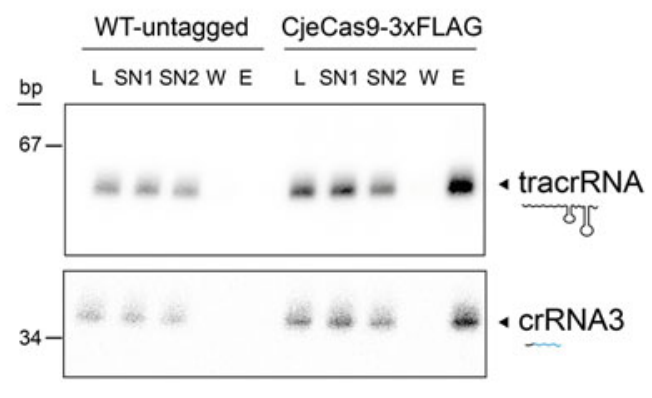

Fig. 2 Quality control for colP of CjeCas9-3XFLAG and co-purified RNAs using western and northern blotting. (a) Protein eluates collected post IP are subjected to $10 \%$ SDS-polyacrylamide gel electrophoresis. $20 \mu \mathrm{L}$ sample from lysate, SN1, SN2, wash, and eluate fractions from the untagged WT control strain and the CjeCas9-3xFLAG tagged strain samples were probed with anti-FLAG and anti-GroEL (control) antibodies using the same blot. CjeCas9 is specifically enriched in the CjeCas9-3xFLAG samples and absent in untagged WT samples, confirming successful immunoprecipitation. The presence of IgG heavy (Hc) and light (LC) chains in both WT and CjeCas9-3xFLAG elution samples indicates successful capture of the FLAG antibody by protein-A beads. (b) RNA eluates collected post immunoprecipitation are subjected to 6\% PAA/7M urea gel electrophoresis followed by northern blotting. $5 \mu \mathrm{L}$ RNA sample each from lysate, SN1, SN2, wash, and eluate fractions of WT and CjeCas9-3xFLAG were used for northern blotting and blots were probed with ATP $(\gamma-32 \mathrm{P})$ labeled DNA oligonucleotides complementary to tracrRNA and crRNA3 to confirm their enrichment in CjeCas9-3xFLAG tagged samples. Representative western and northern blots are shown 
3. Incubate the reaction mix for $45 \mathrm{~min}$ at $37^{\circ} \mathrm{C}$. Then add $1 \mu \mathrm{L}$ DNase I to the tube, mix and spin down the reaction mix. Incubate at $37^{\circ} \mathrm{C}$ for further $15 \mathrm{~min}$.

4. After $15 \mathrm{~min}$, add $50 \mu \mathrm{L}$ RNase-free water to adjust the reaction volume to a total of $100 \mu \mathrm{L}$.

5. Add $100 \mu \mathrm{L} \mathrm{P/C/I} \mathrm{to} \mathrm{stop} \mathrm{the} \mathrm{reaction} \mathrm{for} \mathrm{all} \mathrm{samples} \mathrm{and}$ transfer the total volume to PLG tubes. Make sure to spin down the PLG tubes before use. Mix by rigorous shaking and afterwards centrifuge at $15,000 \times \mathfrak{g}, 15^{\circ} \mathrm{C}$ for $12 \mathrm{~min}$.

6. Transfer the aqueous phase to a fresh $2 \mathrm{~mL}$ Eppendorf tube and add 2.5 volumes $(\sim 200 \mu \mathrm{L})$ of $30: 1 \mathrm{mix}$ of Ethanol:3M sodium acetate. Incubate overnight at $-20{ }^{\circ} \mathrm{C}$ for RNA precipitation.

7. On the next day, centrifuge at $15,000 \times g, 4^{\circ} \mathrm{C}$ for $30 \mathrm{~min}$. Carefully remove supernatant and wash the pellet with $350 \mu \mathrm{L}$ of $70 \%$ Ethanol (stored at $-20^{\circ} \mathrm{C}$ ). Centrifuge at $15,000 \times \mathfrak{g}$, $4{ }^{\circ} \mathrm{C}$ for $10 \mathrm{~min}$.

8. Remove the supernatant and air-dry the RNA pellet in a laminar hood.

9. Resuspend the pellet in $30 \mu \mathrm{L}$ RNase-free water, incubate at $65{ }^{\circ} \mathrm{C}$ on a heat block with constant shaking at $800 \mathrm{rpm}$ for $5 \mathrm{~min}$, and store at $-20{ }^{\circ} \mathrm{C}$ for use later. Confirm successful depletion of genomic DNA using $1 \mu \mathrm{L}$ of DNase I treated RNA as a template for a control PCR to amplify a gene of choice, with genomic DNA template serving as a positive control. If the product is still amplified in DNase I treated RNA sample, repeat DNase treatment for the sample(s).

3.5 cDNA Library Preparation, Sequencing, and Analysis
All RNA samples post DNase I treatment can be directly used for cDNA synthesis for Illumina sequencing without prior sizeselection, fragmentation, or rRNA depletion. Methodological details of cDNA sequencing and analysis are beyond the scope of this chapter. An example protocol for CDNA library preparation has been previously described [31]. Other cDNA library preparation protocols can also be used based on instructions provided by the manufacturer. Here we describe the downstream data analysis workflow using our recently published data from our CjeCas9 RIP-seq analysis [31].

Briefly, RIP-seq analysis of CjeCas9 aims to identify enriched RNAs specifically bound to the protein. Sequencing of cDNA fragments generated from CjeCas9 co-purified RNAs leads to identification of individual reads, each of which can be computationally mapped to the reference genome. After sequencing and quality control steps, coverage plots are generated representing the number of mapped reads per nucleotide which can be used for visualization in a genome browser such as the Integrated Genome 
A

Genome-wide coverage of co-purified RNAs identified with CjeCas9 RIP-seq
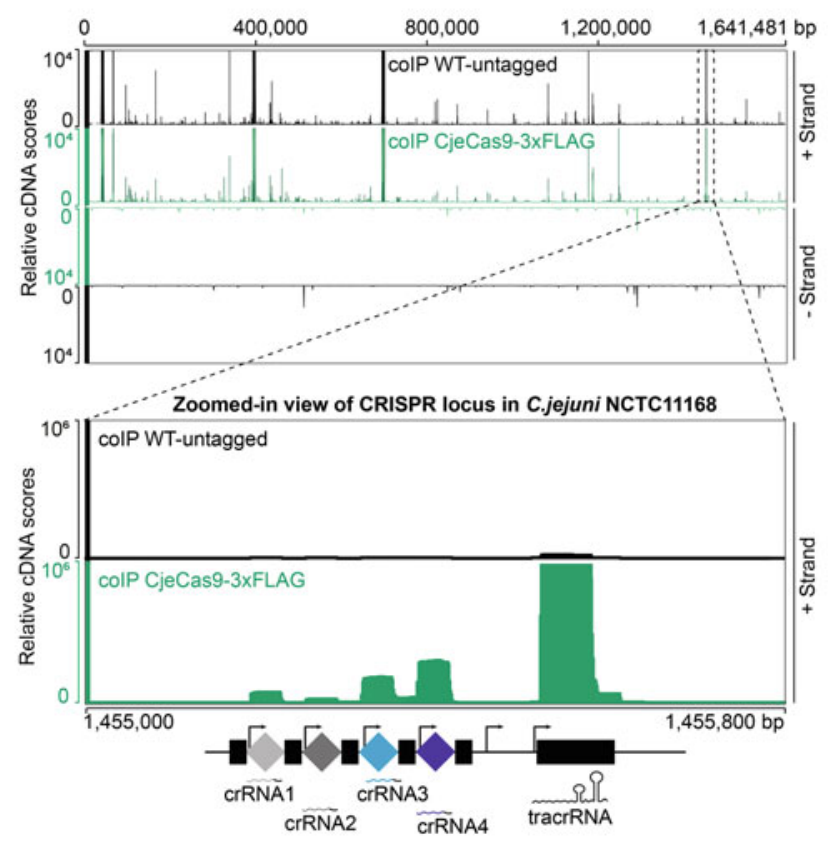

B Different classes of enriched RNAs identified from RIP-seq

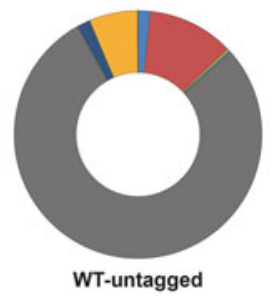

ErRNAs DORFs ErRNAs inacrRNA ETRAs

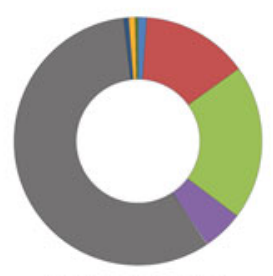
Eseudogenes

CjeCas9-3xFLAG IIRNAs E' UTR hkRNAs

C

Input: CjeCas9-3xFLAG vs WT enriched sequenced reads

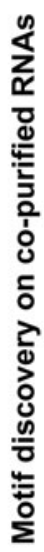

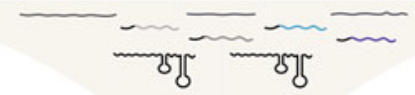

Identify enriched peaks (sliding-window, RIP-seeker, piranha)

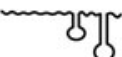

tracrRNA

MEME analysis for other peaks

Motif 1

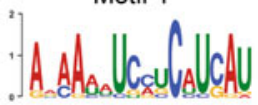

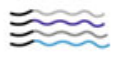

crRNAs
Expected peaks (positive control)

\footnotetext{
Analyse motif sequences for complementarity to other peaks or consensus binding to the IPed protein
Sequence complementarity Sequence complementarity identified for crRNA3 identified for crRNA4

Fig. 3 Visualizing RIP-seq results and downstream analysis. (a) RIP-seq results for Cas9 from C.jejuni strain NCTC11168 [31]. (Upper panel) Screenshot of CDNA coverage plots of normalized RNA-seq reads from untagged WT control (black) and CjeCas9-3xFLAG colP (green) libraries mapped to the $C$. jejuni NCTC11168 genome (both strands) and visualized using the Integrated Genome Browser. (Lower panel) A zoomed-in screenshot of the normalized RNA-seq reads from WT and CjeCas9-3xFLAG colP libraries mapped to the CRISPR locus is shown to highlight the enrichment of crRNAs and tracrRNA in the CjeCas9-3xFLAG tagged 
Browser (IGB) or Integrative Genomics Viewer (IGV) $[52,53]$. This enables a direct visual comparison of relative cDNA reads for WT-untagged and epitope-tagged libraries mapped to a particular locus of choice, as shown for CRISPR locus, allowing for better interpretation of the data (Fig. 3a). Transcript quantification can then be performed between the CjeCas9-3xFLAG and WT coIP libraries and the resulting count data can be used for differential expression analysis via DESeq2 [55] to generate enrichment scores, thereby identifying RNA targets specifically bound to CjeCas9. Furthermore, the co-purified transcripts can be grouped according to functional classes based on the annotations. In the CjeCas9 RIP-seq example, the most abundantly co-purified RNA classes in the WT and CjeCas9-3xFLAG coIP library reads belong to ribosomal RNA (rRNA), transfer RNA (tRNA), and the housekeeping RNAs (hkRNAs). This is not surprising as rRNAs and tRNAs constitute more than $95 \%$ of the total cellular RNA pool and can be nonspecifically bound during the coIP approach. However, they are typically not enriched in the library of the tagged RBP vs the WT control and thus can be excluded as potential binding partners. On the other hand, a strong enrichment of the tracrRNA and all four crRNAs only in CjeCas9-3xFLAG coIP library indicates specific binding to CjeCas9. Moreover, a striking observation during the RIP-seq analysis of CjeCas9 was the enrichment of RNAs aside from tracrRNA and crRNAs in the CjeCas9 coIP library (Fig. 3b). Most of the additionally enriched RNAs corresponded to regions from open reading frames (ORFs), indicating co-purification of messenger RNAs with CjeCas9. Some of them

Fig. 3 (continued) versus WT coIP sample. Genomic coordinates and relative number of cDNA reads are indicated next to each screenshot. (b) Read distribution of different RNA classes depicted as doughnut charts showing the relative proportions of mapped CDNA reads in the CjeCas9-3xFLAG and WT coIP libraries. The RNA classes include ribosomal RNAs (rRNAs), messenger RNAs (ORFs), $5^{\prime}$ untranslated regions ( $5^{\prime}$ UTRs), pseudogenes, house-keeping RNAs (hkRNAs), transfer RNAs (tRNAs), small RNAs (sRNAs), the tracrRNA, and the four crRNAs of $C$. jejuni strain NCTC11168. ORFs (red), crRNAs (violet), and tracrRNA (green) were highly enriched while other RNA classes were depleted following immunoprecipitation and sequencing of co-purified RNAs from CjeCas9-3xFLAG colP library versus the untagged WT colP library. (c) Workflow for peak detection and motif discovery used for CjeCas9-3xFLAG bound co-purified RNAs. Normalized coverage files generated post cDNA sequencing of the CjeCas9 colP vs. WT control colP libraries were subjected to a peak-detection algorithm based on a sliding-window approach [31]. The resulting peaks were used as input for MEME analysis [54] and revealed the presence of two distinct motifs in several of the co-purified transcripts. These motifs were further analyzed regarding sequence and base-pairing probability to identify potential RNA:RNA interactions within the CjeCas9-bound interactome. Motif 1 and 2 displayed complementarity to the guide portion of crRNA3 and crRNA4 encoded in C. jejuni NCTC11168, indicating that these transcripts are bound by CjCas9 in a crRNA-dependent manner [31] 
showed defined enriched peaks in the Cas9-3xFLAG coIP compared to the WT coIP sample.

Besides a manual annotation of such enriched peaks across the genome, numerous peak-detection tools are available for analyzing RIP-seq data such as RIP-seeker [56], Piranha [57], and our in-house peak-detection algorithm based on a sliding-window approach [31]. The resulting peaks enriched in the CjeCas93XFLAG coIP library can then be used to identify the presence of distinct motifs using MEME analysis [54]. In our study, MEME led to the identification of two motifs in most of the co-purified mRNAs. These motifs showed base-pairing complementarity to the sequences of the crRNA3 and crRNA4 guides encoded naturally in the host system, hinting at direct RNA:RNA interactions and association with the CjeCas9:crRNA:tracrRNA RNP (Fig. 3c). Depending on the RNA-binding protein used for coIP, the motifs could also indicate the binding site specificity of the RBP [40]. Bioinformatic programs such as IntaRNA or NUPACK can be used to examine base-pairing probabilities between the crRNAs and additional co-purified transcripts $[58,59]$. Once computationally identified, it is important to confirm and validate the identified RNA: RNA interactions via other methods such as genetic manipulation of identified RNAs or direct biochemical assays which confer specificity to the identified RNAs and associated RNPs in the studied organism. For example, using deletion strains of either individual crRNAs [31] or the whole CRISPR array for performing RIP-seq could help validate direct crRNA-dependent RNA:RNA interactions and identify other potential crRNA-independent interactions with CRISPR-Cas proteins of interest, respectively. In addition, RIP-seq data can be analyzed together with additional available transcriptome data such as differential RNA-sequencing (dRNAseq) data to distinguish between the enriched primary transcripts marked by a $5^{\prime}$ tri-phosphate ( $\left.5^{\prime} \mathrm{PPP}\right)$ and processed RNAs with a $5^{\prime}$ monophosphate $\left(5^{\prime} \mathrm{P}\right)$ group $[60,61]$. dRNA-seq has facilitated the identification of transcriptional start sites and small RNAs and helped to decipher processing of CRISPR-derived RNAs in the human pathogen Streptococcus pyogenes via tracrRNA [19]. The same approach also helped to uncover distinct crRNA biogenesis mechanisms, leading to the discovery of a new subtype C of Type II CRISPR-Cas systems in N. meningitidis and C. jejuni [62, 63].

3.6 Outlook

Molecular mechanisms underlying CRISPR-Cas adaptive immunity have been extensively studied over the past decade. While a lot has been uncovered for individual CRISPR systems, networks governing regulation of these systems within the host are yet unknown. Most organisms typically contain a single CRISPR system, while some employ more than one. The interplay between different CRISPR defense systems in varied hosts is crucial for their survival under native conditions. Among all the differences 
between the CRISPR-Cas classes, types, and subtypes, there lies one commonality: all use RNA-guided ribonucleoprotein complexes. Thus, it is important to know how the RNA guides of these complexes look like and whether RNAs other than system specific crRNAs or tracrRNAs can also be associated with these complexes. A method to study RNP complexes on a transcriptome-wide scale like RIP-seq can help to identify such RNAs. Depending on what is known regarding the CRISPR-Cas protein of interest, other RNA-seq based global pull-down approaches such as CLIP-seq, RIL-seq, or CLASH could also be employed [64-66]. In CLIP-seq, the protein of interest is crosslinked to its interacting RNAs by ultraviolet light in vivo, immunoprecipitated, and bound RNAs are sequenced. This allows for refinement of precise binding sites on RNA as the crosslinking is detected by a change in the nucleotide sequence. The RIL-seq and CLASH approaches capture RNA-RNA pairs by adding a ligation step while the RNAs are in close proximity to the protein of interest post crosslinking and immunoprecipitation [3]. Application of such techniques can help ascertain whether the RNAs are bound directly or indirectly via RNA-RNA interactions to different Cas proteins in varied CRISPR systems and would help shed light on hostmediated regulation and other possible roles for these effector proteins and adaptive immune systems.

\section{Notes}

1. RIP-seq experiments can be performed in Gram-positive or Gram-negative bacteria to identify RNA substrates of a CRISPR-Cas protein-of-interest (POI). The amount of required cell starting material can vary between 20 and $60 \mathrm{OD}_{600}$ depending on the expression of the POI and chosen growth condition.

2. To keep expression levels of the POI to physiological levels, it is recommended that the POI is chromosomally tagged using a $3 x F L A G$ tag or any other epitope of choice. It is preferred, if a monoclonal antibody is available against the epitope, else the pull-down can be performed using a polyclonal antibody/antiserum. In organisms where genome manipulation is difficult, plasmids can also be used to express the POI. It is important to note that expressing a POI on a plasmid will generate an additional copy of the protein and both genome and plasmidencoded variants will compete for the same RNAs, leading to an enrichment of plasmid-encoded POI-bound RNAs after sequencing. The copy number of the plasmid should be chosen as to generate levels of the POI in the range of physiological levels and growth kinetics should be monitored to detect any 
phenotypic changes upon overexpression of the POI before proceeding with the RIP-seq experiment.

3. Ideally, the POI can be tagged either at its $\mathrm{N}$ - or C-terminus. It is advisable to check for expression and activity of the POI post epitope tagging at either end. Once this is verified, strains harboring the epitope-tagged POI should be compared with the untagged WT strain to rule out potential growth defects.

4. If possible, western blotting should be performed following growth curve analysis of the untagged and epitope-tagged strain. Samples collected at different growth phases (lag, early-log, mid-log, late-log/early stationary, and stationary phase) and analyzed on a western blot will help to identify the ideal growth condition, where the expression of the POI is strong enough for immunoprecipitation. Also, initial screening with a western blot helps to confirm the predicted size $(\mathrm{kDa})$ of the tagged POI.

5. The volume of resuspension Buffer A can vary depending on the pellet. This step is performed to wash the cells off the remaining medium and any metabolic waste products generated by the cells, which might affect the subsequent steps of immunoprecipitation.

6. It is important to adjust the volume of the Lysis buffer depending on the amount of bacterial culture pelleted. The volume of the Lysis buffer should be just enough to resuspend the pellet but not dilute it. This should be standardized based on the model organism and the pellet collected. Lysis buffer volumes could impact the overall lysis. In case of volumes exceeding $1 \mathrm{~mL}$, the volume must be equally distributed over two to three fast-prep tubes. After lysis and centrifugation, cleared lysates belonging to the same samples can be pooled together for immunoprecipitation.

7. Bacterial cell lysis using a FastPrep-24 machine or other physical disruption methods should be standardized based on the model organism. Before collecting pellets for RIP-seq, parameters such as the amount of bacterial culture and lysis method need to be standardized. This can be done by visualizing the epitope-tagged POI present post-lysis using a western blot. For Gram-positive cells, this might mean increasing the number of cycles and cycle-times on the FastPrep machine. Also, it is important to maintain native conditions for immunoprecipitation of RNA substrates and samples must be kept on ice throughout the protocol. A larger pellet volume does not necessarily lead to better lysis and more protein starting material for immunoprecipitation.

8. The volume of aliquots collected for RNA/protein fractions will vary depending on the starting volume of the Lysis buffer, 
culture pellet and the volume of the cleared lysate recovered post-lysis.

9. To aliquot the beads from its stock, it is recommended to use an autoclaved bottom-cropped $1000 \mu \mathrm{L}$ tip. To bottom-crop, simply cut $2-3 \mathrm{~mm}$ from the bottom of the $1000 \mu \mathrm{L}$ tip using sterile scissors.

10. The incubation time of the lysate with the anti-FLAG and protein A-sepharose beads can be standardized for each POI. It should be kept in mind that longer incubation times might be detrimental and thus lead to nonspecific binding which might not reflect physiologically relevant RNA:RNA or RNA: protein interactions.

11. It is recommended to store the rest of the SN2 fraction until quality control of the experiment is completed. If the POI is not enriched in the eluate fraction as visualized using western blot, the leftover SN2 fraction can help ascertain whether the POI was bound to the beads or was lost during washing steps of the immunoprecipitation protocol.

12. Care must be taken while performing the washing steps. Any loss of beads is directly proportional to the loss of bound RNPs, thus affecting the analysis.

13. TRIZOL can also be used to recover RNA at this step, following the instructions provided by the manufacturer. It is advisable to add GlycoBlue ${ }^{\mathrm{TM}}$ blue to facilitate RNA precipitation, as the RNA yields obtained from immunoprecipitation can be quite low. GlycoBlue ${ }^{\mathrm{TM}}$ acts as a carrier, thus aiding in RNA recovery and visualization of the pellet after centrifugation.

14. Using a combination of a $200 \mu \mathrm{L}$ tip on top of a $1000 \mu \mathrm{L}$ tip aids in complete removal of the supernatant, without disturbing the pellet. This is a crucial step and any loss of pellets should be avoided.

15. As the protein pellet might be difficult to see among the beads, it is advisable to be cautious while washing and care must be taken to prevent any loss of beads or the protein pellet.

16. Performing a western blot to confirm successful immunoprecipitation of the POI is strongly recommended. This allows to ascertain if the POI was sufficiently enriched in the eluate from the epitope-tagged strain versus the untagged strain. This step also aids in standardization of the coIP protocol by visualizing the tagged protein in other fractions collected (lysate, SNl, $\mathrm{SN} 2$, and wash) during the course of the experiment. Performing a northern blot is dependent on the knowledge of previously identified RNAs (acting as positive controls) associated with the POI and can also be excluded if such information is not at hand. In any case, the western blot should 
confirm enrichment of the POI prior to proceeding with cDNA library preparation of co-purified transcripts.

\title{
Acknowledgments
}

\begin{abstract}
We would like to thank the members of the Sharma lab for their contributions towards adapting and further developing the RIP-seq protocol for use in Epsilonproteobacteria over the years and Thorsten Bischler from the Core Unit Systems Medicine, University of Würzburg for help with RIP-seq data analysis. We thank Elisabetta Fiore and Mona Alzheimer for critical comments on this book chapter. This work was supported by DFG (Deutsche Forschungsgemeinschaft) grant SH 580/9-1 to C.M.S. within the priority program SPP 2141 "Much more than defence: the multiple functions and facets of CRISPR-Cas."
\end{abstract}

\section{References}

1. Beckmann BM, Castello A, Medenbach J (2016) The expanding universe of ribonucleoproteins: of novel RNA-binding proteins and unconventional interactions. Pflugers Arch 468:1029-1040. https://doi.org/10.1007/ s00424-016-1819-4

2. Babitzke P, Lai Y-J, Renda AJ, Romeo T (2019) Posttranscription initiation control of gene expression mediated by bacterial RNA-binding proteins. Annu Rev Microbiol 73:43-67. https://doi.org/10.1146/ annurev-micro-020518-115907

3. Saliba A-E, Santos SC, Vogel J (2017) New RNA-seq approaches for the study of bacterial pathogens. Curr Opin Microbiol 35:78-87. https://doi.org/10.1016/j.mib.2017.01.001

4. Hör J, Gorski SA, Vogel J (2018) Bacterial RNA biology on a genome scale. Mol Cell 70:785-799. https://doi.org/10.1016/j. molcel.2017.12.023

5. Koonin EV, Makarova KS, Zhang F (2017) Diversity, classification and evolution of CRISPR-Cas systems. Curr Opin Microbiol 37:67-78. https://doi.org/10.1016/j.mib. 2017.05.008

6. Marraffini LA, Sontheimer EJ (2010) CRISPR interference: RNA-directed adaptive immunity in bacteria and archaea. Nat Rev Genet 11:181-190. https://doi.org/10.1038/ $\operatorname{nrg} 2749$

7. van der Oost J, Jore MM, Westra ER et al (2009) CRISPR-based adaptive and heritable immunity in prokaryotes. Trends Biochem Sci
34:401-407. https://doi.org/10.1016/j.tibs. 2009.05.002

8. Hille F, Richter H, Wong SP et al (2018) The biology of CRISPR-Cas: backward and forward. Cell 172:1239-1259. https://doi.org/ 10.1016/j.cell.2017.11.032

9. Wright AV, Nuñez JK, Doudna JA (2016) Biology and applications of CRISPR systems: harnessing nature's toolbox for genome engineering. Cell 164:29-44. https://doi.org/10. 1016/j.cell.2015.12.035

10. Mohanraju P, Makarova KS, Zetsche B et al (2016) Diverse evolutionary roots and mechanistic variations of the CRISPR-Cas systems. Science 353:aad5147. https://doi.org/10. $1126 /$ science.aad5147

11. Makarova KS, Wolf YI, Iranzo J et al (2020) Evolutionary classification of CRISPR-Cas systems: a burst of class 2 and derived variants. Nat Rev Microbiol 18:67-83. https://doi. org/10.1038/s41579-019-0299-x

12. Barrangou R, Fremaux C, Deveau $\mathrm{H}$ et al (2007) CRISPR provides acquired resistance against viruses in prokaryotes. Science 315:1709-1712. https://doi.org/10.1126/ science. 1138140

13. Marraffini LA, Sontheimer EJ (2008) CRISPR interference limits horizontal gene transfer in staphylococci by targeting DNA. Science 322:1843-1845. https://doi.org/10.1126/ science. 1165771

14. Terns MP (2018) CRISPR-based technologies: impact of RNA-targeting systems. Mol Cell 
72:404-412. https://doi.org/10.1016/j. molcel.2018.09.018

15. Wang F, Wang L, Zou X et al (2019) Advances in CRISPR-Cas systems for RNA targeting, tracking and editing. Biotechnol Adv 37:708-729. https://doi.org/10.1016/j.bio techadv.2019.03.016

16. Jinek M, Chylinski K, Fonfara I et al (2012) A programmable dual-RNA-guided DNA endonuclease in adaptive bacterial immunity. Science 337:816-821. https://doi.org/10. $1126 /$ science. 1225829

17. Gasiunas G, Barrangou R, Horvath P, Siksnys V (2012) Cas9-crRNA ribonucleoprotein complex mediates specific DNA cleavage for adaptive immunity in bacteria. Proc Natl Acad Sci U S A 109:E2579-E2586. https://doi. org/10.1073/pnas.1208507109

18. Jiang F, Doudna JA (2017) CRISPR-Cas9 structures and mechanisms. Annu Rev Biophys 46:505-529. https://doi.org/10.1146/ annurev-biophys-062215-010822

19. Deltcheva E, Chylinski K, Sharma CM et al (2011) CRISPR RNA maturation by transencoded small RNA and host factor RNase III. Nature 471:602-607. https://doi.org/ $10.1038 /$ nature 09886

20. Anders C, Niewoehner O, Duerst A, Jinek M (2014) Structural basis of PAM-dependent target DNA recognition by the Cas9 endonuclease. Nature 513:569-573. https://doi.org/ 10.1038 /nature 13579

21. Westra ER, Buckling A, Fineran PC (2014) CRISPR-Cas systems: beyond adaptive immunity. Nat Rev Microbiol 12:317-326. https:// doi.org/10.1038/nrmicro3241

22. Louwen R, Horst-Kreft D, de Boer AG et al (2013) A novel link between Campylobacter jejuni bacteriophage defence, virulence and Guillain-Barré syndrome. Eur J Clin Microbiol Infect Dis 32:207-226. https://doi.org/10. 1007/s10096-012-1733-4

23. Hale CR, Majumdar S, Elmore J et al (2012) Essential features and rational design of CRISPR RNAs that function with the Cas RAMP module complex to cleave RNAs. Mol Cell 45:292-302. https://doi.org/10.1016/j. molcel.2011.10.023

24. Zegans ME, Wagner JC, Cady KC et al (2009) Interaction between bacteriophage DMS3 and host CRISPR region inhibits group behaviors of Pseudomonas aeruginosa. J Bacteriol 191:210-219. https://doi.org/10.1128/JB . 00797-08

25. Mandin P, Repoila F, Vergassola M et al (2007) Identification of new noncoding RNAs in Listeria monocytogenes and prediction of mRNA targets. Nucleic Acids Res 35:962-974. https://doi.org/10.1093/nar/gkll096

26. Vercoe RB, Chang JT, Dy RL et al (2013) Cytotoxic chromosomal targeting by CRISPR/Cas systems can reshape bacterial genomes and expel or remodel pathogenicity islands. PLoS Genet 9:e1003454. https://doi. org/10.1371/journal.pgen.1003454

27. Babu M, Beloglazova N, Flick R et al (2011) A dual function of the CRISPR-Cas system in bacterial antivirus immunity and DNA repair. Mol Microbiol 79:484-502. https://doi.org/ $10.1111 /$ j.1365-2958.2010.07465.x

28. Viswanathan P, Murphy K, Julien B et al (2007) Regulation of dev, an operon that includes genes essential for Myxococcus xanthus development and CRISPR-associated genes and repeats. J Bacteriol 189:3738-3750. https://doi.org/10.1128/JB.00187-07

29. Gunderson FF, Cianciotto NP (2013) The CRISPR-associated gene cas2 of Legionella pneumophila is required for intracellular infection of amoebae. MBio 4:e00074-e00013. https://doi.org/10.1128/mBio.00074-13

30. Ratner HK, Escalera-Maurer A, Le Rhun A et al (2019) Catalytically active cas9 mediates transcriptional interference to facilitate bacterial virulence. Mol Cell 75:498-510.e5. https://doi.org/10.1016/j.molcel.2019.05. 029

31. Dugar G, Leenay RT, Eisenbart SK et al (2018) CRISPR RNA-dependent binding and cleavage of endogenous RNAs by the Campylobacter jejuni Cas9. Mol Cell 69:893-905.e7. https://doi.org/10.1016/j.molcel.2018.01. 032

32. Strutt SC, Torrez RM, Kaya E et al (2018) RNA-dependent RNA targeting by CRISPRCas9. elife. https://doi.org/10.7554/eLife. 32724

33. Rousseau BA, Hou Z, Gramelspacher MJ, Zhang Y (2018) Programmable RNA cleavage and recognition by a natural CRISPR-Cas9 system from Neisseria meningitidis. Mol Cell 69:906-914.e4. https://doi.org/10.1016/j. molcel.2018.01.025

34. O'Connell MR, Oakes BL, Sternberg SH et al (2014) Programmable RNA recognition and cleavage by CRISPR/Cas9. Nature 516:263-266. https://doi.org/10.1038/ nature 13769

35. Nelles DA, Fang MY, O'Connell MR et al (2016) Programmable RNA tracking in live cells with CRISPR/Cas9. Cell 165:488-496. https://doi.org/10.1016/j.cell.2016.02.054

36. Zhang A, Wassarman KM, Rosenow $\mathrm{C}$ et al (2003) Global analysis of small RNA and 
mRNA targets of Hfq. Mol Microbiol 50:1111-1124. https://doi.org/10.1046/j. 1365-2958.2003.03734.x

37. Christiansen JK, Nielsen JS, Ebersbach T et al (2006) Identification of small Hfq-binding RNAs in Listeria monocytogenes. RNA 12:1383-1396. https://doi.org/10.1261/ rna.49706

38. Sonnleitner E, Sorger-Domenigg T, Madej MJ et al (2008) Detection of small RNAs in Pseudomonas aeruginosa by RNomics and structure-based bioinformatic tools. Microbiology 154:3175-3187. https://doi.org/10. $1099 /$ mic.0.2008/019703-0

39. Sittka A, Lucchini S, Papenfort K et al (2008) Deep sequencing analysis of small noncoding RNA and mRNA targets of the global posttranscriptional regulator, Hfq. PLoS Genet 4: el000163. https://doi.org/10.1371/journal. pgen.1000163

40. Dugar G, Svensson SL, Bischler T et al (2016) The CsrA-FliW network controls polar localization of the dual-function flagellin mRNA in Campylobacter jejuni. Nat Commun 7:11667. https://doi.org/10.1038/ncomms11667

41. Rieder R, Reinhardt R, Sharma C, Vogel J (2012) Experimental tools to identify RNA-protein interactions in Helicobacter pylori. RNA Biol 9:520-531. https://doi. org/10.4161/rna.20331

42. Bilusic I, Popitsch N, Rescheneder P et al (2014) Revisiting the coding potential of the E. coli genome through $\mathrm{Hfq}$ co-immunoprecipitation. RNA Biol 11:641-654. https://doi.org/10.4161/rna. 29299

43. Göpel Y, Papenfort K, Reichenbach B et al (2013) Targeted decay of a regulatory small RNA by an adaptor protein for RNase E and counteraction by an anti-adaptor RNA. Genes Dev 27:552-564. https://doi.org/10.1101/ gad.210112.112

44. Heidrich N, Bauriedl S, Schoen C (2019) Investigating RNA-Protein interactions in Neisseria meningitidis by RIP-Seq analysis. Methods Mol Biol 1969:33-49. https://doi. org/10.1007/978-1-4939-9202-7_3

45. Heidrich N, Bauriedl S, Barquist L et al (2017) The primary transcriptome of Neisseria meningitidis and its interaction with the RNA chaperone Hfq. Nucleic Acids Res 45:6147-6167. https://doi.org/10.1093/nar/gkxl68

46. Michaux C, Holmqvist E, Vasicek E et al (2017) RNA target profiles direct the discovery of virulence functions for the cold-shock proteins CspC and CspE. Proc Natl Acad Sci U S A
114:6824-6829. https://doi.org/10.1073/ pnas.1620772114

47. Gerovac M, El Mouali Y, Kuper J et al (2020) Global discovery of bacterial RNA-binding proteins by RNase-sensitive gradient profiles reports a new FinO domain protein. RNA 26:1448-1463. https://doi.org/10.1261/ rna.076992.120

48. Zhang J, Rouillon C, Kerou M et al (2012) Structure and mechanism of the CMR complex for CRISPR-mediated antiviral immunity. Mol Cell 45:303-313. https://doi.org/10.1016/j. molcel.2011.12.013

49. Brunelle JL, Green R (2014) One-dimensional SDS-polyacrylamide gel electrophoresis (1D SDS-PAGE). Methods Enzymol 541:151-159. https://doi.org/10.1016/ B978-0-12-420119-4.00012-4

50. Brown T, Mackey K, Du T (2004) Analysis of RNA by northern and slot blot hybridization. Curr Protoc Mol Biol Chapter 4:Unit 4.9. https://doi.org/10.1002/0471142727. mb0409s67

51. He SL, Green R (2013) Northern blotting. Methods Enzymol 530:75-87. https://doi. org/10.1016/B978-0-12-420037-1. 00003-8

52. Robinson JT, Thorvaldsdóttir H, Winckler W et al (2011) Integrative genomics viewer. Nat Biotechnol 29:24-26. https://doi.org/10. $1038 /$ nbt. 1754

53. Freese NH, Norris DC, Loraine AE (2016) Integrated genome browser: visual analytics platform for genomics. Bioinformatics 32:2089-2095. https://doi.org/10.1093/bio informatics/btw069

54. Bailey TL, Boden M, Buske FA et al (2009) MEME SUITE: tools for motif discovery and searching. Nucleic Acids Res 37:W202-W208. https://doi.org/10.1093/nar/gkp335

55. Love MI, Huber W, Anders S (2014) Moderated estimation of fold change and dispersion for RNA-seq data with DESeq2. Genome Biol 15:550. https://doi.org/10.1186/s13059014-0550-8

56. Li Y, Zhao DY, Greenblatt JF, Zhang Z (2013) RIPSeeker: a statistical package for identifying protein-associated transcripts from RIP-seq experiments. Nucleic Acids Res 41:e94. https://doi.org/10.1093/nar/gkt142

57. Uren PJ, Bahrami-Samani E, Burns SC et al (2012) Site identification in high-throughput RNA-protein interaction data. Bioinformatics 28:3013-3020. https://doi.org/10.1093/bio informatics/bts569

58. Mann M, Wright PR, Backofen R (2017) IntaRNA 2.0: enhanced and customizable 
prediction of RNA-RNA interactions. Nucleic Acids Res 45:W435-W439. https://doi.org/ $10.1093 / \mathrm{nar} / \mathrm{gkx} 279$

59. Zadeh JN, Steenberg CD, Bois JS et al (2011) NUPACK: Analysis and design of nucleic acid systems. J Comput Chem 32:170-173. https://doi.org/10.1002/jcc.21596

60. Sharma CM, Hoffmann S, Darfeuille F et al (2010) The primary transcriptome of the major human pathogen Helicobacter pylori. Nature 464:250-255. https://doi.org/10. 1038 /nature08756

61. Heidrich N, Dugar G, Vogel J, Sharma CM (2015) Investigating CRISPR RNA biogenesis and function using RNA-seq. Methods Mol Biol 1311:1-21. https://doi.org/10.1007/ 978-1-4939-2687-9_1

62. Zhang Y, Heidrich N, Ampattu BJ et al (2013) Processing-independent CRISPR RNAs limit natural transformation in Neisseria meningitidis. Mol Cell 50:488-503. https://doi.org/ 10.1016/j.molcel.2013.05.001

63. Dugar G, Herbig A, Förstner KU et al (2013) High-resolution transcriptome maps reveal strain-specific regulatory features of multiple
Campylobacter jejuni isolates. PLoS Genet 9: el003495. https://doi.org/10.1371/journal. pgen.1003495

64. Melamed S, Peer A, Faigenbaum-Romm R et al (2016) Global Mapping of Small RNA-Target Interactions in Bacteria. Mol Cell 63:884-897. https://doi.org/10.1016/j.molcel.2016.07. 026

65. Waters SA, McAteer SP, Kudla G et al (2017) Small RNA interactome of pathogenic E. coli revealed through crosslinking of RNase E. EMBO J 36:374-387. https://doi.org/10. 15252/embj.201694639

66. Holmqvist E, Wright PR, Li L et al (2016) Global RNA recognition patterns of posttranscriptional regulators $\mathrm{Hfq}$ and CsrA revealed by UV crosslinking in vivo. EMBO J 35:991-1011. https://doi.org/10.15252/ embj.201593360

67. Jiao C, Sharma S, Dugar G, et al (2021) Noncanonical crRNAs derived from host transcripts enable multiplexable RNA detection by Cas9. Science 372:941-948. https://doi.org/ $10.1126 /$ science.abe7106

Open Access This chapter is licensed under the terms of the Creative Commons Attribution 4.0 International License (http://creativecommons.org/licenses/by/4.0/), which permits use, sharing, adaptation, distribution and reproduction in any medium or format, as long as you give appropriate credit to the original author(s) and the source, provide a link to the Creative Commons license and indicate if changes were made.

The images or other third party material in this chapter are included in the chapter's Creative Commons license, unless indicated otherwise in a credit line to the material. If material is not included in the chapter's Creative Commons license and your intended use is not permitted by statutory regulation or exceeds the permitted use, you will need to obtain permission directly from the copyright holder. 